\title{
Human Neutrophil Cytochrome b Light Chain (p22-phox) \\ Gene Structure, Chromosomal Location, and Mutations in Cytochrome-negative Autosomal Recessive Chronic Granulomatous Disease
}

\author{
Mary C. Dinauer, ${ }^{\star}$ Eric A. Pierce, ${ }^{\star}$ Gail A. P. Bruns, ${ }^{\ddagger}$ John T. Curnutte, ${ }^{5}$ and Stuart H. Orkin ${ }^{\star \prime}$ \\ ${ }^{*}$ Division of Hematology-Oncology, Children's Hospital, and the Dana Farber Cancer Institute, Department of Pediatrics, and \\ ${ }^{\ddagger}$ Division of Genetics, Children’s Hospital, Department of Pediatrics, Harvard Medical School, Boston, Massachusetts 02115; \\ ${ }^{\S}$ Department of Molecular and Experimental Medicine, Scripps Clinic, La Jolla, California 92037; and "Howard Hughes Medical \\ Institute, Boston, Massachusetts 02115
}

\begin{abstract}
A membrane-bound cytochrome $b$, a heterodimer formed by a 91-kD glycoprotein (heavy chain) and a $22-\mathrm{kD}$ polypeptide (light chain), is an essential component of the phagocyte NADPH-oxidase responsible for superoxide generation. $\mathrm{Cy}$ tochrome $b$ is absent in two subgroups of chronic granulomatous disease (CGD), an inherited disorder characterized by the lack of oxidase activity. Mutations in the cytochrome heavy chain gene, encoded by the CYBB locus in Xp21.1, result in the $\mathrm{X}$-linked form of CGD. A rare subgroup of autosomal recessive CGD also lacks cytochrome $b$ (A- CGD), but the genetic defect has not previously been identified. In order to search for possible mutations in the cytochrome light chain locus, CYBA, the structure of this gene was characterized. The CYBA locus was localized to $16 q 24$, and the $\approx 600$-bp open reading frame determined to be encoded by six exons that span $\approx 8.5 \mathrm{~kb}$. Three unrelated patients with $A^{-}$CGD were studied for evidence of mutations in the light chain gene. One patient, whose parents were first cousins, was homozygous for a large deletion that removed all but the extreme $5^{\prime}$ coding sequence of the gene. The other two patients had a grossly normal light chain transcript on Northern blot of mononuclear cell RNA. The light chain transcript was amplified by the polymerase chain reaction and sequenced. One patient was a compound heterozygote for two alleles containing point mutations in the open reading frame that predict a frame shift and a nonconservative amino acid replacement, respectively. The second patient, whose parents were second cousins, was homozygous for a different single-base substitution resulting in another nonconservative amino acid change. These results indicate that $A^{-}$CGD can result from defects in the gene encoding the 22-kD light chain of the phagocyte cytochrome b. (J. Clin. Invest. 1990. 86:1729-1737.) Key words: phagocyte • NADPH-oxidase • superoxide $\bullet$ chromosome 16
\end{abstract}

\section{Introduction}

A phagocyte-specific cytochrome $b$ is an essential component of the phagocyte NADPH-oxidase, a membrane-associated

Published in abstract form in the 1989 issue of Blood. 74:107a. (Abstr.) Address reprint requests to Dr. Dinauer, Division of HematologyOncology, Children's Hospital, Boston, MA 02115.

Received for publication 3 May 1990 and in revised form 25 June 1990.

J. Clin. Invest.

(c) The American Society for Clinical Investigation, Inc.

$0021-9738 / 90 / 11 / 1729 / 09 \$ 2.00$

Volume 86, November 1990, 1729-1737 enzyme system that generates the superoxide radical (1-3). The cytochrome has an unusually low midpoint potential and is postulated to serve as the terminal redox carrier in the transfer of electrons from NADPH to oxygen (4). Current evidence indicates that the functional oxidase complex also includes multiple other components, including several cytosolic proteins required for activity of the otherwise dormant oxidase (5-7). Upon cellular stimulation, large quantities of superoxide are formed and converted into toxic oxidants important for microbicidal activity and inflammatory tissue injury.

The phagocyte cytochrome $b$ is a membrane-bound oligomer, probably a heterodimer, of a 91-kD glycoprotein, gp91phox (also known as the $\beta$ or heavy chain), and a 22-kD subunit, p22-phox ( $\alpha$ or light chain) $(8,9)$. The primary amino acid sequences of the heavy and light chains, as deduced from their corresponding cDNAs, have no obvious homology to known proteins, including other cytochromes $(10,11)$, and the functional domains of the two cytochrome subunits have not been defined. The heavy and light chains are closely associated in purified preparations, and denaturation is required to separate the two polypeptides $(8,9)$. Despite the close physical interaction of the two cytochrome chains, the corresponding mRNA transcripts appear to be independently regulated. Whereas expression of the $91-\mathrm{kD}$ heavy chain transcript is restricted to phagocytic cells, the mRNA for the 22-kD light chain is present in many cell types $(10,11)$. Nevertheless, the $22-\mathrm{kD}$ protein is readily detected only in phagocytic cells that also contain the heavy chain (11). This observation suggests that assembly of the cytochrome heterodimer markedly influences the intracellular stability of its constituent chains. It is uncertain whether low levels of the light chain might serve any function in nonphagocytic cells.

Compelling genetic evidence for the functional importance of the phagocyte oxidase and the critical role of cytochrome $b$ is provided by studies of chronic granulomatous disease (CGD). ${ }^{1}$ In this inherited disorder, phagocytic cells are unable to generate superoxide, and affected individuals develop severe and recurrent infections $(1,12)$. CGD is genetically heterogenous, reflecting lesions in different components of the oxidase. The 91-kD subunit of cytochrome $b$ is encoded by the CYBB locus (for $\beta$ chain) in band Xp21.1 $(13,14)$. Mutations in this gene result in X-linked recessive CGD $(2,3,10)$, which includes $\approx 65 \%$ of all cases of CGD, and account for the consistent absence of the cytochrome $b$ heme spectrum originally noted in this subset (15). Despite the genetic deficiency of only the $91-\mathrm{kD}$ subunit, both heavy and light chains are lacking in

1. Abbreviations used in this paper: ASO, allele-specific oligonucleotides; CGD, chronic granulomatous disease; $P C R$, polymerase chain reaction. 
X-linked CGD $(2,8,9)$, consistent with a model in which intracellular stability of the $22-\mathrm{kD}$ species depends upon association with the larger subunit.

Most autosomal recessive forms of CGD have normal cytochrome $b$ levels (A ${ }^{+}$CGD) (15), and lack either p47-phox or p67-phox, two soluble proteins required for intact oxidase function (5-7, 16-18). However, a rare subgroup of autosomal recessive CGD resembles the $\mathrm{X}$-linked form in that both chains of cytochrome $b$ are absent (A- CGD) (19). Specific genetic defects in $\mathrm{A}^{-}$CGD have not yet been identified. This subgroup may have mutations in the gene for the 22-kD light chain of cytochrome $b$, with a secondary lack of the $91-\mathrm{kD}$ protein due to failure of cytochrome assembly. Alternatively, the genetic defect might involve other, as yet unidentified proteins, required for expression or assembly of the cytochrome chains.

Here we report the structure of the gene for the $22-\mathrm{kD}$ light chain of cytochrome $b$ and its chromosomal location, which serve as a foundation for the analysis of genetic abnormalities at this locus in chronic granulomatous disease. Three unrelated patients with autosomal recessive, cytochrome-negative CGD were studied, and found to have four different mutations in the cytochrome light chain gene.

\section{Methods}

Materials. Restriction enzymes were purchased from New England Biolabs, Beverly, MA, and Boehringer-Mannheim, Indianapolis, IN. pUC and M13 vectors were from Pharmacia Fine Chemicals, Piscataway, $\mathrm{NJ}$, and radiolabeled deoxynucleotides were from Amersham Corp., Arlington Heights, IL. Synthetic nucleotides were prepared on a DNA synthesizer (model 340B; Applied Biosystems, Inc., Foster City, CA). Sequenase (modified T7 polymerase) and kits for DNA sequencing by the dideoxynucleotide chain termination method were from U. S. Biochemicals, Cleveland, $\mathrm{OH}$. Avian myeloblastosis virus reverse transcriptase was obtained from Molecular Genetic Resources, Tampa, FL, and RNAsin from Promega Biotec, Madison, WI. Taq DNA polymerase was from Perkin-Elmer Corp., Norwalk, CT/Cetus Corp., Emeryville, CA. All other reagents used were of analytical grade or better.
Screening of genomic library and analysis of genomic sequences of 22-kD cytochrome $b$ light chain. A Sau3A partial-digest $\lambda$ EMBL 3A bacteriophage library prepared from human leukocyte DNA (20) was screened by plaque hybridization (21) using a radiolabeled (22) $0.7-\mathrm{kb}$ cDNA probe for the 22-kD cytochrome $b$ light chain (clone 17, which starts 28 nucleotides upstream from the initiator ATG and extends through the poly(A) tail [11]). Positive phage clones were plaque purified, and phage DNA analyzed by restriction digests and blot hybridization using established methods (21). Genomic fragments containing the 22-kD sequence were subcloned into pUC for additional mapping. Intron-exon boundaries were identified by DNA sequence analysis using a Sequenase kit after alkaline denaturation of the plasmid.

Restriction mapping of genomic DNA and Northern blot analysis of $R N A$. High molecular weight genomic DNA was isolated from peripheral blood cell nuclei or tissue culture cells (23) and aliquots digested with restriction enzymes according to the manufacturer's suggestions. Digests were fractionated on a $0.8 \%$ agarose gel, transferred to nitrocellulose, and hybridized with the 22-kD cDNA clone 17 probe using standard techniques (21). RNA was prepared from peripheral blood mononuclear cells using guanidine- $\mathrm{HCl}$ precipitation and subjected to denaturing gel electrophoresis for Northern blot analysis as described (24) using cDNA probes for cytochrome $b$ heavy and light chains (1.4-kb Pst I-Eco RI cDNA fragment (10) and clone 17, respectively).

Chromosomal location of gene for 22-kD cytochrome b light chain. DNAs from a panel of rodent-human hybrids containing various human chromosomes $(25,26)$ were digested with Sac I and subjected to Southern blot analysis, using the 22-kD cDNA clone 17 as a probe In situ hybridization to metaphase chromosome preparations of normal peripheral blood lymphocytes was performed as described, with tritium-labeled cDNA clone 17 as the probe (27).

DNA amplification and characterization of amplified sequences. Amplification primers were 33- to 47-mers derived from 22-kD cDNA or genomic sequences, and included restriction enzyme sites at their $5^{\prime}$ ends (Bam HI, Eco RI, or Hind III) to facilitate subcloning (Table I). Segments of the 22-kD gene were amplified from 1.0- $\mu \mathrm{g}$ samples of genomic DNA using the polymerase chain reaction (PCR) and Taq DNA polymerase under conditions suggested by the manufacturer, with the following modifications to improve the efficiency of amplifcation of sequences high in $(G+C)$ content. The dNTP mix contained $50 \mu \mathrm{M}$ dGTP and $150 \mu \mathrm{M}$ 7-deaza-2'-GTP (28); remaining dNTPs were each at $200 \mu \mathrm{M}$. Samples were incubated at $94^{\circ}$ for 1 to $1.5 \mathrm{~min}$, then $72^{\circ}$ for 3 to $4 \mathrm{~min}$, for a total of 35 to 40 cycles. In the case of exon 6 , sequential amplification of genomic DNA with nested primers

Table I. Sequence of Oligonucleotide Primers

\begin{tabular}{ll}
\hline 1 & 5' CAGTGTCCCAGCCGGGTTCGTGTC 3' (2) \\
$2^{*}$ & 5' TTGGGCTCGATGGGCGTCCACTGC 3' (438) \\
3 & 5' GCCATTGCGAGCGGCATCTACCTA 3' (371) \\
$4^{*}$ & 5' CTGCTTGATGGTGCCTCCGATCTG 3' (478) \\
5 & 5' AGCAGTGGACGCCATCGAGCCCAAG 3' (414) \\
$6^{*}$ & 5' ATTGCAGGTGGGTGCACCTGGTGGGAG 3' (661) \\
$7^{*}$ & 5' TGCAAGTAGCCCGAGGTCCCGGCTGGGGTCTT 3' (intron I) \\
8 & 5' TGCTTGTGGGTAAACCAAGGCCGGTG 3' (intron III) \\
$9^{*}$ & 5' GTTGTTTGGAAAAACACTGAGGTAAGTGGGGGTGGT 3' (intron IV) \\
10 & 5' CTGGGTCTGCAGTCTGCCTTGTCCTGA 3' (intron IV) \\
$11^{*}$ & 5' GCTCACACTTGCTCCCAGCCTTGGCTCAGCCTACAGA 3' (intron V) \\
12 & 5' GGAAGGCGATGCTGATGTTAATGAAA (3' untranslated)
\end{tabular}

Oligonucleotides 1-12 were used as primers for PCR. Primers 1-6 were derived from the cDNA sequence for the 22-kD light chain of cytochrome $b(11)$ and used for amplification of cDNA samples. The number in parentheses indicates the position within the cDNA sequence of the most $5^{\prime}$ nucleotide of the primer. Oligonucleotides 7-12 were derived from genomic sequences flanking exons $1,4,5$, and 6 of the light chain gene (unpublished data), and used to amplify these exons, respectively, from genomic DNA. In addition to the nucleotides displayed here, all primers contained a sequence of 10 nucleotides at their $5^{\prime}$ ends that began with 4 random nucleotides followed by a Bam HI, Eco RI, or Hind III restriction site to facilitate subcloning. * Antisense strand. 
(primers 5 and 12 followed by primers 5 and 6; Table I) was performed to generate sufficient product. For analysis of mRNA sequences, first strand cDNA was synthesized from mononuclear cell RNA and amplified by PCR as previously described (24), but with the inclusion of the modifications noted above. As smaller fragments amplified more efficiently, three overlapping fragments of the cDNA sequence were generated for sequence analysis.

For DNA sequence analysis, amplified DNA fragments were digested with the appropriate restriction enzymes, purified on a nondenaturing polyacrylamide gel, and cloned into pUC or M13 derivatives for sequencing. Because of the possibility of heterozygosity, multiple independent clones were sequenced. No random nucleotide substitutions due to misincorporation by Taq polymerase were noted.

Allele-specific hybridization was performed essentially as described (24) to identify single-base substitutions in exons 4,5 , and 6 , which were amplified from genomic DNA samples. Allele-specific oligonucleotides (ASO) were prepared for a CAC $\rightarrow$ TAC substitution at nucleotide position 242 (numbered with respect to the published cDNA sequence [11]) that predicts a His-72 $\rightarrow$ Tyr substitution (His-1 ASO = CAGAAGCACATGACCGC, Tyr ASO = GCGGTCATGTACTTCTG [antisense]). In addition, hybridization with an oligonucleotide specific for the alternative histidine codon CAT was examined (His-2 ASO = CAGAAGCATATGACCGC). ASO probes were also prepared for three other substitutions first identified in CGD patients: (a) G-297 $\rightarrow$ A, which predicts an Arg-90 $\rightarrow$ Gln mutation (Arg90 ASO $=$ TATGTTCGGGCCGTCCT, Gln90 ASO $=$ TATGTT CAGGCCGTCCT); (b) C-382 $\rightarrow$ A, which predicts a Ser-1 $18 \rightarrow$ Arg substitution (Ser118 ASO = AGATGCCGCTCGCAATG, Arg1 18 ASO = AGATGCCTCTCGCAATG (both antisense)); (c) C-549 $\rightarrow$ T, which predicts an Ala-174 $\rightarrow$ Val substitution (Ala174 ASO $=$ AGGAGGCTGCGGCGGCG, Val $174=$ AGGAGGCTGCGGTGGCG).

\section{Results}

Isolation of genomic clones and mapping of cytochrome b light chain gene. Three independent recombinant $\lambda E M B L 3 A$ bacteriophage were isolated from a human genomic library by screening with a cDNA probe containing the entire coding region of the 22-kD light chain mRNA and flanking untranslated sequence (Fig. $1 A$ ). A composite restriction map deduced from these clones and genomic Southern blots (see below) is shown in Fig. $1 B$. Exon positions were determined by Southern blotting of restriction digests of bacteriophage DNA and hybridization with oligonucleotides derived from the cDNA sequence. Blot hybridization of bacteriophage DNA with labeled total genomic DNA indicated the widespread distribution of repetitive sequences throughout the cloned region. To identify additional restriction sites outside the cloned sequences and to confirm that no gross rearrangements had occurred during the cloning procedure, Southern blotting of genomic DNA digests and hybridization with the cDNA probe was also performed (not shown). The observed fragments were consistent with those predicted from the bacteriophage maps.

The most $5^{\prime}$ bacteriophage clone, A9 (Fig. $1 A$ ), ended within the coding sequence five nucleotides downstream from the initiator ATG. Repeated screenings of the library failed to yield any clones containing the upstream $5^{\prime}$ coding and untranslated sequence. The entire gene appears to be encompassed within two Sac I fragments, as determined by Southern blot hybridization of genomic DNA (not shown), which suggests that the $5^{\prime}$ untranslated region and the initiator ATG are within $1.5 \mathrm{~kb}$ of the $5^{\prime}$ end of A9 (Fig. $1 \mathrm{~B}$ ). To determine if an intron interrupts the sequence near the initiator ATG, we attempted to amplify this region by PCR from genomic DNA. One primer was derived from the $5^{\prime}$ untranslated cDNA sequence, and the second primer corresponded to genomic sequence residing 100-130 nucleotides downstream from the $5^{\prime}$ end of $A 9$ (primers 1 and 7 ; Table I). $A \approx 170$-bp fragment was amplified, compatible with the lack of any intervening sequence between the initiator ATG and the $5^{\prime}$ end of clone A9. This was confirmed by DNA sequencing of the amplified fragment.

As shown in Fig. $1 B$, the numbering of light chain exons used in this report designates the exon containing the initiator ATG as "1". However, the existence of additional upstream exons containing 5 ' untranslated sequence has not been formally excluded.

Exon-intron structure of coding region of light chain gene. The structure of the entire coding region of the gene for the cytochrome $b$ light chain was characterized by analysis of genomic bacteriophage clones and PCR amplification of genomic DNA, as described above. This region spans $\approx 8.5 \mathrm{~kb}$ and is divided into six exons (Fig. $1 B$ ) that specify a predicted primary translation product of 195 amino acids. Exons and their corresponding intron boundaries were located and sequenced using genomic clone A9. Table II displays intronexon sizes and their boundary sequences. All splice junction sequences conform to the GT/AG rule (29). Exon 6 encodes the $\mathrm{COOH}$-terminal 72 residues (37\% of the protein), a sequence notable for a proline content of $\approx 25 \%$, as well as the entire 66-bp 3 ' untranslated region. The remaining exons each encode 20-25 amino acids.

Identification of a polymorphism at His-72. Comparison of cDNA and genomic sequences revealed a CAC $\rightarrow$ TAC substitution at nucleotide position 242 of the published cDNA sequence (11), which predicts the nonconservative replacement of His-72 with a tyrosine residue. Because the histidine residue is a candidate for a coordinating ligand of the heme prosthetic group of cytochrome $b$, we investigated whether this sequence discrepancy represented a cloning artefact or a poly-

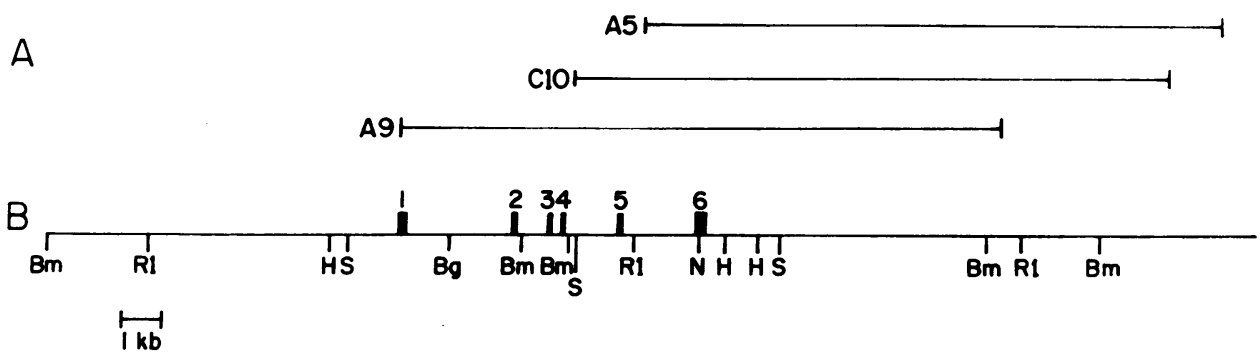

Figure 1. Gene structure for the 22-kD light chain of phagocyte cytochrome $b$. Bacteriophage clones isolated from a human genomic library using a light chain cDNA probe were analyzed by restriction mapping, Southern blot hybridization, and DNA sequencing. $(A)$ Relative location of genomic inserts of overlapping bacteriophage clones A5, C10, and A9. (B) Location of exon sequences (solid bars, numbered 1-6) and restriction sites (B, Bam HI; $R 1$, Eco RI; $H$, Hind III; $S$, Sac I; $B g$, Bgl II; $N$, Not I). 
Table II. Intron-Exon Boundary Sequences of Human Neutrophil Cytochrome b Light Chain

\begin{tabular}{|c|c|c|c|c|c|}
\hline \multirow[t]{2}{*}{ Intron } & \multicolumn{2}{|c|}{$5^{\prime}$ Boundary } & \multirow[t]{2}{*}{ Intron length } & \multicolumn{2}{|c|}{ 3' Boundary } \\
\hline & 86 & & & & 87 \\
\hline I. & $\begin{array}{l}\text { TCC GGC CTG A } \\
\text { Ser Gly Leu }\end{array}$ & gtgagtgcacgt & $\approx 2.6 \mathrm{~kb}$ & ttctccccgcag & $\begin{array}{l}\text { TC CTC ATC } \\
\text { Ile Leu Thr }\end{array}$ \\
\hline & 156 & & & & 157 \\
\hline II. & $\begin{array}{l}\text { TAC TCC AT } \\
\text { Tyr Ser Ile }\end{array}$ & gtatccttccac & $\approx 0.8 \mathrm{~kb}$ & acatggcttcag & $\begin{array}{l}\text { T GTG GCG GGC } \\
\text { Val Ala Gly }\end{array}$ \\
\hline & 231 & & & & 232 \\
\hline III. & $\begin{array}{l}\text { GAG CGC TG } \\
\text { Glu Arg Trp }\end{array}$ & gtgagtctcct & $\approx 0.26 \mathrm{~kb}$ & cctcceccag & $\begin{array}{l}\text { G GGA CAG AAG } \\
\text { Gly Gln Lys }\end{array}$ \\
\hline & 315 & & & & 316 \\
\hline IV. & $\begin{array}{l}\text { CAT CTC CT } \\
\text { His Leu Leu }\end{array}$ & gtgagtcccc $\ldots \ldots$ & $\approx 1.5 \mathrm{~kb}$ & gtccccccag & $\begin{array}{l}\text { G CTC TCG GTG } \\
\text { Leu Ser Val }\end{array}$ \\
\hline & 397 & & & & 398 \\
\hline V. & $\begin{array}{l}\text { TAC CTA CTG } \\
\text { Tyr Leu Leu }\end{array}$ & gtgagtggcg $\ldots \ldots$ & $\approx 1.8 \mathrm{~kb} \ldots \ldots$ & tgcccgcag & $\begin{array}{l}\text { GCG GCT GTG } \\
\text { Ala Ala Val }\end{array}$ \\
\hline
\end{tabular}

Intron sequence data for the 22-kD cytochrome light chain gene have been submitted to GenBank (Accession number pending).

morphism. Exon 4, which contains C/T-242, was amplified from genomic DNA samples obtained from 18 random controls using primers 8 and 9 (Table I). Hybridization with ASO probes demonstrated that the $\mathrm{C} \rightarrow \mathrm{T}$ substitution first identified in the genomic bacteriophage clone represented a sequence polymorphism, with each allele detected in normal genomic DNA (representative samples shown in Fig. 2). None of the samples hybridized with an ASO specific for the alternative histidine codon usage CAT (not shown). Five individuals were homozygous for C-242, the His-72 allele, four were homozygous for T-242, the Tyr-72 allele, and the remaining nine were heterozygous for both alleles.

Chromosomal location of light chain gene. Southern blots of genomic DNA isolated from a panel of human-rodent somatic cell hybrids were probed with cDNA for the human cytochrome $b$ light chain. The presence of human light chain sequences was correlated with the presence of human chromosome 16 (Table III). To map the light chain gene more precisely, in situ hybridization of metaphase chromosomes was also performed. The results of analysis of 100 metaphase spreads is shown in Fig. 3. Of the 187 silver grains recorded, 14 (7.5\%) were located on or near band $16 \mathrm{q} 24$.
Mutatations in cytochrome b light chain gene in autosomal recessive, cytochrome-negative $C G D$. A rare subgroup of autosomal recessive CGD ( $\left.\mathrm{A}^{-} \mathrm{CGD}\right)$ resembles the X-linked form in that both subunits of cytochrome $b$ are absent in immunoblots of solubilized neutrophils (19). Specific genetic defects in $\mathrm{A}^{-}$CGD, however, have not yet been identified. We investigated the genetic basis of cytochrome $b$ deficiency in three unrelated patients with this form of CGD. Patient 1 , a female, has been reported previously $(19,30-32)$. Her parents were first cousins (both clinically well). There is no known consanguinity in the pedigree of patient 2 , a male, who has been reported previously $(19,31,32)$. One of his sisters also had CGD (33) and died from infectious complications. Patient 3, a female, has not previously been reported; her parents are second cousins. Neutrophils from all three patients lack both the 91- and 22-kD cytochrome $b$ polypeptides, and NADPH-oxidase activity is undetectable, with failure of patient membranes to undergo activation in the cell-free oxidase assay even in the presence of normal cytosol $(19,31,32$; and unpublished results).

We first assessed the expression of mRNAs for the cytochrome subunits in peripheral blood mononuclear cells. As

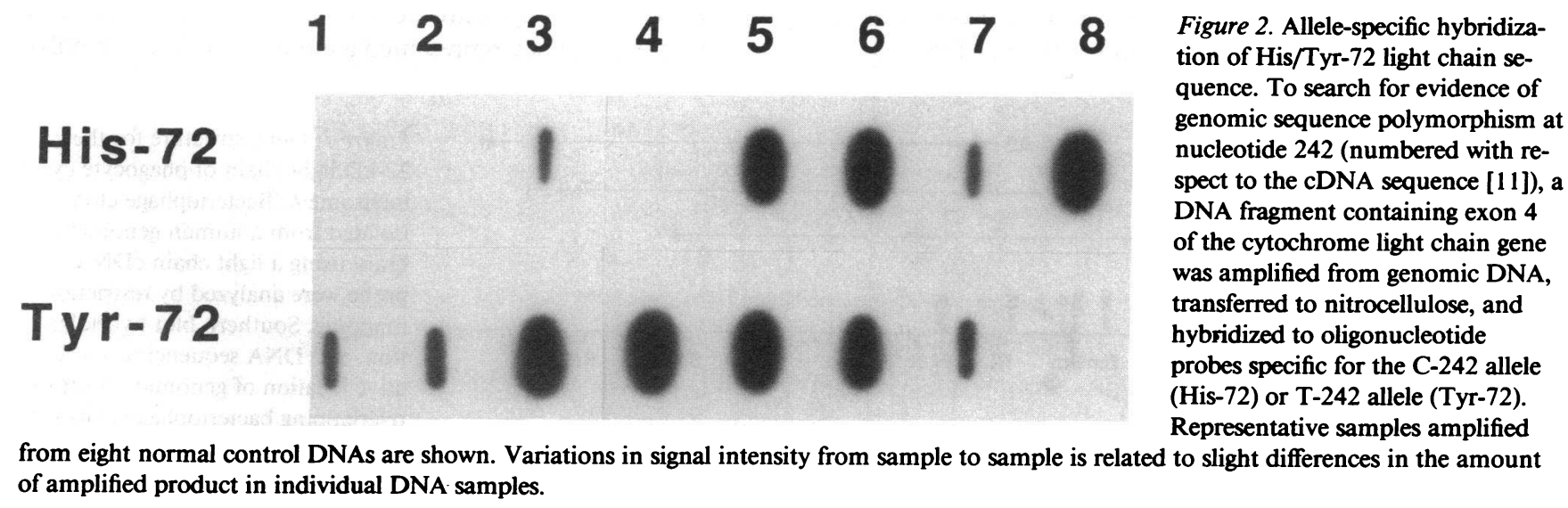


Table III. Segregation Pattern of 22-kD Cytochrome $b$ Light Chain Gene with DNAs from Human-Rodent Somatic Cell Hybrids

\begin{tabular}{|c|c|c|c|c|c|}
\hline \multirow[t]{2}{*}{ Chromosome* } & \multicolumn{4}{|c|}{ Segregation pattern $n^{*}$} & \multirow[t]{2}{*}{$\begin{array}{l}\text { Discordancy } \\
\text { fraction }\end{array}$} \\
\hline & $+/+$ & $-1-$ & $+/-$ & $-1+$ & \\
\hline 1 & 2 & 5 & 5 & 0 & 0.42 \\
\hline 2 & 1 & 4 & 4 & 1 & 0.50 \\
\hline 3 & 4 & 4 & 3 & 1 & 0.33 \\
\hline 4 & 2 & 3 & 3 & 2 & 0.50 \\
\hline 5 & 3 & 4 & 4 & 1 & 0.42 \\
\hline 6 & 4 & 4 & 3 & 1 & 0.33 \\
\hline 7 & 2 & 5 & 5 & 0 & 0.42 \\
\hline 8 & 5 & 2 & 2 & 2 & 0.36 \\
\hline 9 & 3 & 5 & 4 & 0 & 0.42 \\
\hline 10 & 2 & 3 & 4 & 2 & 0.55 \\
\hline 11 & 4 & 4 & 2 & 1 & 0.27 \\
\hline 12 & 3 & 4 & 4 & 1 & 0.42 \\
\hline 13 & 3 & 3 & 4 & 2 & 0.50 \\
\hline 14 & 5 & 3 & 1 & 2 & 0.27 \\
\hline 15 & 1 & 3 & 6 & 2 & 0.67 \\
\hline 16 & 7 & 5 & 0 & 0 & 0.00 \\
\hline 17 & 2 & 4 & 5 & 1 & 0.50 \\
\hline 18 & 3 & 3 & 4 & 2 & 0.50 \\
\hline 19 and der $19^{\prime \prime}$ & 7 & 3 & 0 & 2 & 0.17 \\
\hline 20 & 6 & 3 & 1 & 1 & 0.17 \\
\hline 21 & 5 & 3 & 2 & 2 & 0.33 \\
\hline 22 & 4 & 5 & 3 & 0 & 0.25 \\
\hline$X$ and $\operatorname{der} X^{\top}$ & 4 & 3 & 3 & 2 & 0.42 \\
\hline Y & 0 & 5 & 7 & 0 & 0.58 \\
\hline
\end{tabular}

* Human chromosome complements of the hybrids were determined by isozyme and cytogenetic techniques (25) and by analysis of hybrid DNAs with cloned DNA probes for each autosome and the $\mathrm{X}$ chromosome. ${ }^{\ddagger}$ Column designations are: $+/+$, hybridization signal and chromosome both present; $-/-$, hybridization and chromosome both absent; $+/-$, hybridization present but chromosome absent; and $-1+$, hybridization absent with chromosome present. ${ }^{\S}$ Hybrids with a rearranged chromosome or where the chromosome was present in $<15 \%$ of cells were excluded for calculation of discordancy fractions. "For the nine hybrid clones derived from fusions with leukocytes from two different $X / 19$ translocation carriers, this category represents the der 19 chromosome. 'This category includes hybrids with an intact $\mathrm{X}$ and those with derX translocation chromosomes.

shown in Fig. 4 , the $\approx 0.8-k b$ light chain transcript was absent in patient 1 , but appeared grossly normal in patient 2 and 3 . All three patients had normal levels of the 4.7-kb RNA for the 91-kD subunit, indicating that absence of cytochrome $b$ was not due to a primary deficiency of a transacting factor required for transcription of the heavy chain gene.

Southern blot analysis of genomic DNA revealed that the absence of RNA for the cytochrome $b$ light chain in patient 1 is secondary to a homozygous deletion in the corresponding gene (Fig. 5). Hybridization with probes derived from cloned genomic sequences indicated that the $5^{\prime}$ end of the deletion occurs near a Bgl II site just downstream from exon 1 (not shown). The minimum size of the deletion is $\approx 10 \mathrm{~kb}$, based on the restriction map of the gene and flanking sequences (Fig. $1 \mathrm{~B}$ ). Whether the deletion ends within the mapped region could not be determined because of the existence of repetitive sequences throughout the $3^{\prime}$ end of the cloned genomic DNA. Southern blot analysis of genomic DNA digests from patients 2 and 3 using the light chain cDNA probe were normal (not shown).

We next sought evidence for more limited mutations in the coding sequence of the cytochrome $b$ light chain gene in patient 2. cDNA was prepared from mononuclear cell RNA, and specific primers used to amplify the light chain sequence by PCR (see Table I). Two different alleles were identified by DNA sequence analysis of individual clones, each of which harbored point mutations that predict the synthesis of an abnormal cytochrome $b$ light chain (Fig. 6). Allele 1 contained the Tyr-72 polymorphism described above, and in addition, a single nucleotide deletion of a cytosine residue. The deletion predicts a frame-shift of the open reading frame beginning after Gly-81, with the mutant protein containing a total of 189 residues. The second allele (allele 2 ) carried a $G \rightarrow A$ transition at nucleotide 297 which predicts the nonconservative substitution of a glutamine residue for Arg-90. To confirm these results, the corresponding genomic sequence (exon 4 of the light chain gene) was amplified from DNA prepared from patient 2 , and DNA sequencing of individual clones demonstrated the two mutant alleles. Allele-specific hybridization of amplified genomic DNA indicated that patient 2 and his mother were heterozygous for the wild-type Arg-90 and mutant Gln-90 alleles, whereas the father and 24 unrelated normal controls were homozygous for Arg-90 (not shown). The mother is homozygous for the His-72 polymorphism, and the father for Tyr-72 (not shown). We therefore infer that the father is likely to carry allele 1 , which contains the Tyr-72 polymorphism and the cytosine deletion, and that the mother carries allele 2 .

The sequence of the 22-kD light chain transcript in patient 3 was determined in a similar fashion. A C $\rightarrow$ A transversion at nucleotide 382 was identified that predicts the nonconservative replacement of Ser-1 18 with an arginine. Amplification of genomic DNA (exon 5) and DNA sequencing showed that patient 3 was homozygous for the mutant allele. Allele-specific hybridization of amplified DNA from 20 normal controls showed only the wild-type allele, in contrast to patient 3 , who was homozygous for Arg-118 (not shown). The patient's parents, second cousins, were not available for study. In addition to the mutation at nucleotide 382 , patient 3 was homozygous for a C-549 $\rightarrow$ T substitution that predicts the conservative replacement of Ala-174 with valine. This substitution appears to be a common polymorphism, as shown by allele-specific hybridization of amplified genomic DNA samples (exon 6) from normal controls (not shown).

The molecular defects in the cytochrome $b$ light chain gene identified in this study are summarized in Table IV.

\section{Discussion}

The phagocyte cytochrome $b$ heterodimer is a critical component of the phagocyte oxidase complex that generates superoxide, as its genetic absence in chronic granulomatous disease results in lack of oxidase activity. The $91-\mathrm{kD}$ glycoprotein subunit of the cytochrome is encoded by the CYBB locus at Xp21.1 $(13,14)$, and the 22-kD light chain locus, designated CYBA, has been mapped in this study to $16 \mathrm{q} 24$. Only the APRT locus (adenine phosphoribosyltransferase) has been 
10

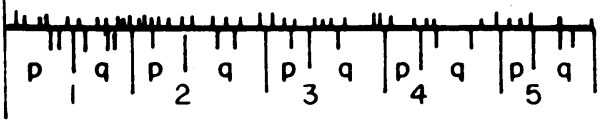

A
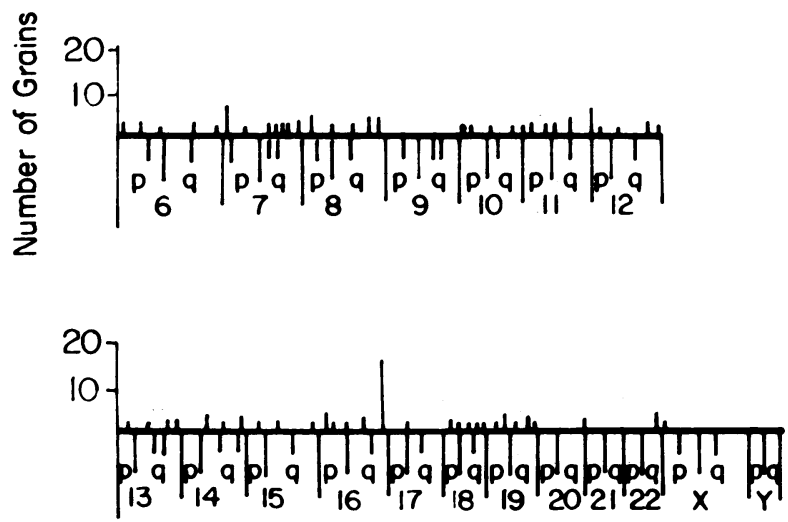

B

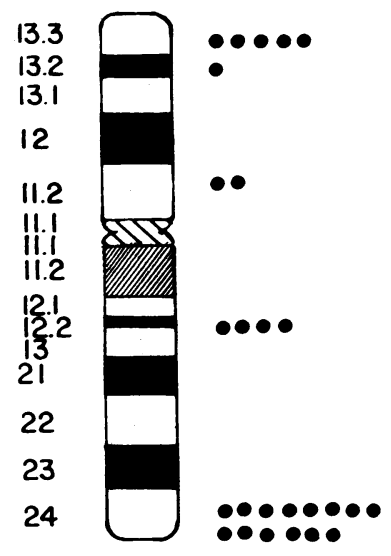

16

\section{Chromosome Number}

Figure 3. Chromosomal location of gene for 22-kD light chain of cytochrome $b$. Results of in situ hybridization of a radiolabeled cDNA probe to human metaphase chromosome spreads are shown. $(A)$ Histogram of the location of 187 grains from a total of 100 metaphases evaluated, with a peak of $14(7.5 \%)$ over the region 16q24. (B) Ideogram of human chromosome 16, showing the distribution of grains (dots on the right), which localize the light chain gene to $16 \mathrm{q} 24$.

previously mapped to $16 \mathrm{q} 24$ (34). The COX4L2 locus (cytochrome $c$ oxidase subunit IV-like 2), a non-heme bearing polypeptide of the mitochondrial cytochrome $c$ oxidase com-

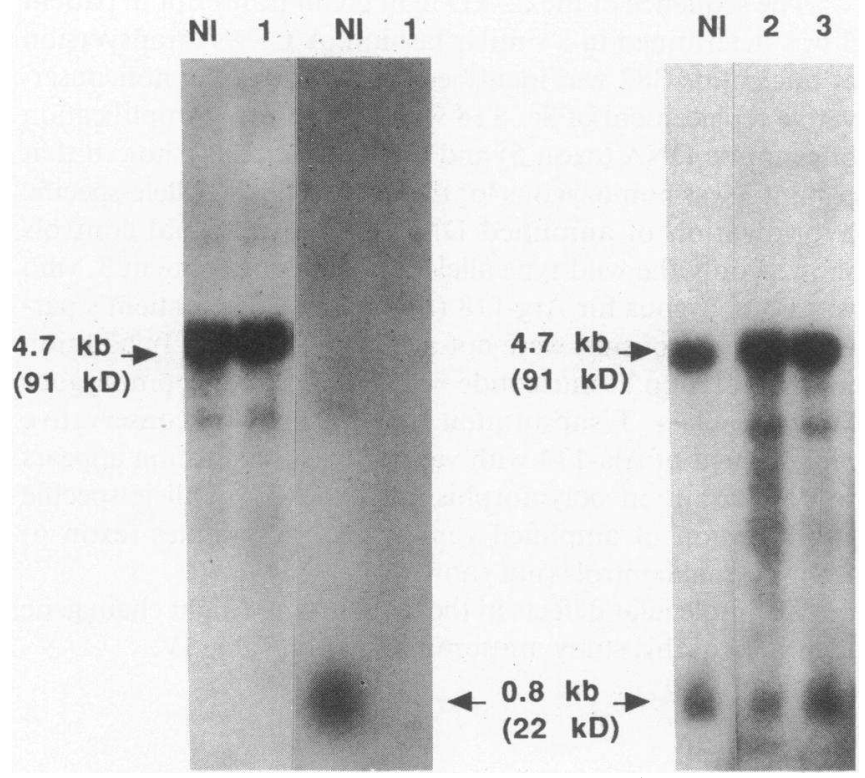

Figure 4. Northern blot analysis of $\mathrm{A}^{-}$CGD. Peripheral blood mononuclear cell RNA was subjected to Northern blot analysis and hybridized with ${ }^{32} \mathrm{P}$-labeled fragments derived from the cytochrome $b$ heavy and light chain cDNAs. Arrows point to the $4.7-\mathrm{kb}$ transcript for the $91-\mathrm{kD}$ heavy chain and $0.8-\mathrm{kb}$ transcript for the $22-\mathrm{kD}$ light chain. N1, normal control; $1,2,3$, patient 1,2 and 3, respectively. RNA from patient 1 was probed for each transcript in separate blots, whereas probes were hybridized simultaneously in the blot of patients 2 and 3 . plex, has been localized to $16 \mathrm{q} 22-24$ (35); there is no obvious cDNA or amino acid sequence homology between this species (36) and the cytochrome light chain. Neither CYBB nor CYBA otherwise reside near known genes for other cytochromes or heme-bearing proteins.

The structure of the cytochrome $b$ light chain gene was determined by a combination of restriction enzyme mapping, Southern blotting, and DNA sequencing of genomic bacteriophage clones. The $\approx 600$-bp open reading frame of the light chain is encoded by six exons that span $\approx 8.5 \mathrm{~kb}$. Whether these divisions correlate with functional subdivisions of the light chain is not yet known, since the functional domains of the phagocyte cytochrome $b$ chains remain to be established. Note that the relatively hydrophobic $\mathrm{NH}_{2}$-terminal portion of the light chain is encoded by 5 exons, whereas the hydrophilic and proline-rich $\mathrm{COOH}$-terminal 72 residues are encoded by a single exon.

The location of the heme in the cytochrome $b$ heterodimer has not been conclusively identified, although there is some evidence that the prosthetic group is associated with the light chain. In one recent report, radiation-inactivation target analysis and sedimentation equilibrium studies, both indirect approaches, localized the heme group to the $22-\mathrm{kD}$ subunit (37). Another group reached the same conclusion after purification of a heme-bearing polypeptide from neutrophils, although this study is problematic in that the amino acid composition of the isolated protein (38) does not resemble that predicted for the 22-kD light chain from its cDNA sequence (11). In this study, a sequence polymorphism was identified that affects one of the two histidine residues originally noted in the $22-\mathrm{kD}$ polypeptide sequence (11) (His/Tyr-72). This observation is noteworthy in that a pair of histidine residues is a likely candidate for the axial ligands of the cytochrome heme group. That the light 


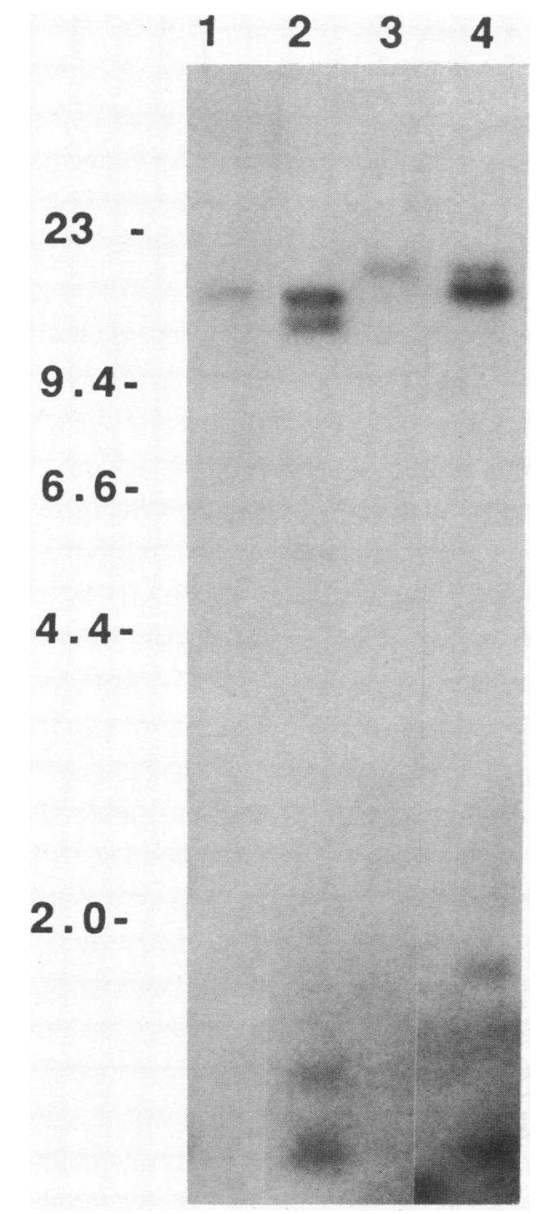

Figure 5. Deletion in 22-kD light chain gene in $\mathrm{A}^{-}$CGD. Genomic DNA was digested with restriction enzymes and analyzed by Southern blot using a radiolabeled cDNA probe for the 22-kD light chain. Lanes 1 and 2, DNA from patient 1 and a normal control, respectively, digested with Bam HI and Eco RI; Lanes 3 and 4, DNA from patient 1 and a normal control, respectively, digested with Bam HI and Bgl II. Numbers on the left are size markers in kilobases.

chain His-72 is not an invariant residue must be taken into account in models for the heme coordinates in the cytochrome $b$ complex.

The genetic basis of the rare, autosomally inherited, cytochrome $b$ negative form of CGD has not been previously established. Mutations in the gene for the cytochrome $b$ light chain were identified in all three patients studied in this report (Table IV). However, it remains possible that some cases of $\mathrm{A}^{-}$ CGD result from mutations at other loci encoding as yet unidentified proteins required for cytochrome $b$ expression. In this study, one patient, the product of a consangineous marriage, was homozygous for a large deletion that removed all but the extreme $5^{\prime}$ end of the light chain gene. Two other patients carried three different point mutations in the light

\section{Wild type}

$\mathrm{C} / \mathrm{T} \mathrm{AC} \quad \ldots . . \mathrm{CCC}$

His / Tyr-72 Pro-82

CGG

Patient 2

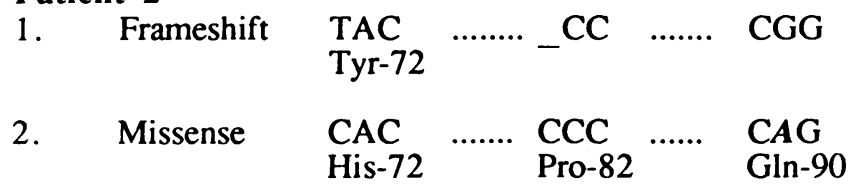

Figure 6. Point mutations in 22-kD light chain in a patient with $\mathrm{A}^{-}$ CGD. Portions of the light chain coding sequence are shown, along with the encoded amino acid residues, numbered according to their position in the protein sequence (11). The wild-type sequence includes a $\mathrm{C} / \mathrm{T}$ polymorphism. Patient 2 is a compound heterozygote for two different single-base alterations identified in PCR-amplified cDNA and genomic DNA samples (allele 1 and 2).

chain gene coding sequence that predict the synthesis of an abnormal polypeptide. One patient was a compound heterozygote for a frame-shift and a missense mutation (Arg-90 $\rightarrow$ Gln), whereas the other was homozygous for a different nonconservative missense mutation (Ser-1 $18 \rightarrow$ Arg). Our data do not directly demonstrate that the missense variants result in a defective cytochrome light chain, as this requires a functional assay for the mutant allele, which is not yet available. However, these mutations did not appear to be polymorphisms and were detected only in the affected patients and the carrier state. Since the cytochrome light chain is absent in immunoblots of neutrophil extracts from these patients, the mutant alleles must direct the synthesis of a polypeptide that is intrinsically unstable or has a defective association with the cytochrome $b$ heavy chain (see below). Both missense mutations reside within a relatively hydrophobic region of the predicted polypeptide, and substitutions in this region might disrupt the normal folding of the light chain or its close interaction with the heavy chain.

It has previously been observed that both the 91 - and 22-kD subunits of the cytochrome heterodimer are absent in the X-linked and autosomal recessive forms of cytochrome $b$-negative CGD (19). X-linked CGD is due to mutations in the gene for the 91-kD heavy chain $(2,3)$, suggesting that intracellular stability of the light chain requires association with the large subunit. The present findings indicate that the converse may also be true, that is, the $91-\mathrm{kD}$ heavy chain is unstable in the absence of binding to the light chain. The stabilizing effect of oligomerization on component polypeptides of multimeric membrane protein complexes has been

Table IV. Mutations in 22-kD Cytochrome b Light Chain Gene in $A^{-} C G D$

\begin{tabular}{|c|c|c|c|c|c|}
\hline Patient & Mutation & RNA & Protein & $\begin{array}{l}\text { Nucleotide } \\
\text { change }\end{array}$ & $\begin{array}{l}\text { Amino acid } \\
\text { change }\end{array}$ \\
\hline $1[19,30-32]$ & $\geq 10$ kb deletion (Homozygous) & - & - & N/A & N/A \\
\hline \multirow[t]{2}{*}{$2[19,31,32]$} & 1) Frameshift & + & - & C-272 deletion & Frameshift \\
\hline & 2) Missense & + & - & $\mathrm{G}-297 \rightarrow \mathrm{A}$ & Arg-90 $\rightarrow$ Gln \\
\hline 3 & Missense (Homozygous) & + & - & $\mathrm{C}-382 \rightarrow \mathrm{A}$ & Ser-1 $18 \rightarrow$ Arg \\
\hline
\end{tabular}

Mutations that predict the synthesis of an abnormal cytochrome light chain (or absent light chain) are listed for the three patients studied in this report. Patient 2 is also a double heterozygote for a His/Tyr-72 polymorphism. Patient 3 is homozygous for a Ala/Val-174 polymorphism (Val allele). N/A, not applicable. 
noted in other systems such as the acetylcholine receptor, the leukocyte integrins, and the T cell receptor (39-41).

The mRNA transcript for the 22-kD light chain appears to be constitutively expressed in a variety of cell lineages, in contrast to the phagocyte-specific expression of the heavy chain transcript, although levels of $22-\mathrm{kD}$ protein are virtually undetectable in nonphagocytic cells (11). Whether low levels of the light chain polypeptide might serve any functional role in nonphagocytic cells has been uncertain. Since the deletion of the majority of the light chain gene produces only the CGD phenotype (patient 1 in this report), it appears unlikely that the 22-kD subunit has any essential function in nonphagocytic cells.

\section{Acknowledgments}

The authors thank the late Dr. S. A. Latt for performing the chromosomal in situ hybridization studies.

Dr. Dinauer is the recipient of a Clinical Investigator Award (K08HL-02253-01), Dr. Curnutte is an Established Investigator of the American Heart Association, and Dr. Orkin is an Investigator of the Howard Hughes Medical Institute. This work was supported in part by grants from the National Institutes of Health (HD-18661, AI-24838, and RR-00833).

\section{References}

1. Curnutte, J. T., and B. M. Babior. 1987. Chronic granulomatous disease. Adv. in Hum. Genet. 16:229-297.

2. Dinauer, M. C., S. H. Orkin, R. Brown, A. J. Jesaitis, and C. A. Parkos. 1987. The glycoprotein encoded by the X-linked chronic granulomatous disease locus is a component of the neutrophil cytochrome b complex. Nature (Lond.). 327:717-720.

3. Teahan, C., P. Rowe, P. Parker, N. Totty and A. W. Segal. 1987. The X-linked chronic granulomatous disease gene codes for the $\beta$ chain of cytochrome b-245. Nature (Lond.). 327:720-721.

4. Segal, A. W. 1989. The electron transport chain of the microbicidal oxidase of phagocytic cells and its involvement in the molecular pathology of chronic granulomatous disease. J. Clin. Invest. 83:17851793.

5. Volpp, B. D., W. M. Nauseef, and R. A. Clark. 1988. Two cytosolic neutrophil oxidase components absent in autosomal chronic granulomatous disease. Science (Wash. DC). 242:1295-1297.

6. Nunoi, H., D. Rotrosen, J. I. Gallin, and H. L. Malech. 1988. Two forms of autosomal chronic granulomatous disease lack distinct neutrophil cytosol factors. Science (Wash. DC). 242:1298-1301.

7. Curnutte, J., P. J. Scott, and L. Mayo. 1989. Cytosolic components of the respiratory burst oxidase: resolution of four components, two of which are missing in complementing types of chronic granulomatous disease. Proc. Natl. Acad. Sci. USA. 86:825-829.

8. Segal, A. W. 1987. Absence of both cytochrome b-245 subunits from neutrophils in X-linked chronic granulomatous disease. Nature (Lond.). 326:88-91.

9. Parkos, C. A., R. A. Allen, C. G. Cochrane, and A. J. Jesaitis. 1987. Purified cytochrome $b$ from human granulocyte plasma membrane is comprised of two polypeptides with relative molecular weights of 91,000 and 22,000. J. Clin. Invest. 80:732-742.

10. Royer-Pokora, B., L. M. Kunkel, A. P. Monaco, S. C. Goff, P. E. Newburger, R. L. Baehner, F. S. Cole, J. T. Curnutte, and S. H. Orkin. 1986. Cloning the gene for an inherited human disorderchronic granulomatous disease-on the basis of its chromosomal location. Nature (Lond.). 322:32-38.

11. Parkos, C. A., M. C. Dinauer, L. E. Walker, R. A. Allen, A. J. Jesaitis, and S. H. Orkin. 1988. Primary structure and unique expression of the 22-kilodalton light chain of human neutrophil cytochrome b. Proc. Natl. Acad. Sci. USA. 85:3319-3323.
12. Tauber, A. I., N. Borregaard, E. Simons, and J. Wright. 1983. Chronic granulomatous disease: a syndrome of phagocyte oxidase deficiencies. Medicine (Baltimore). 62:286-309.

13. Francke, U., H. D. Ochs, B. deMartinville, J. Giacalone, V. Lindren, C. Disteche, R. A. Pagon, M. H. Hofker, G.-J. van Ommen B., P. L. Pearson, and R. J. Wedgwood. 1985. Minor Xp21 chromosome deletion in a male associated with expression of Duchenne muscular dystrophy, chronic granulomatous disease, retinitis pigmentosa, and McLeod syndrome. Am. J. Hum. Genet. 37:250-267.

14. Baehner, R. L., L. M. Kunkel, A. P. Monaco, J. L. Haines, P. M. Conneally, C. Palmer, N. Heerema, and S. H. Orkin. 1986. DNA linkage analysis of $\mathrm{X}$-linked chronic granulomatous disease. Proc. Natl. Acad. Sci. USA. 83:3398-3401.

15. Segal, A. W., A. R. Cross, R. C. Garcia, N. Borregaard, and N. Valerius. 1983. Absence of cytochrome b-245 in chronic granulomatous disease: a multicenter European evaluation of its incidence and relevance. $N$. Engl. J. Med. 308:245-251.

16. Curnutte, J. T., R. L. Berkow, R. L. Roberts, S. B. Shurin, and P. J. Scott. 1988. Chronic granulomatous disease due to a defect in the cytosolic factor required for NADPH oxidase activation. J. Clin. Invest. 81:606-611.

17. Bolscher, B. G. J. M., R. van Zwieten, I. M. Kramer, R. S. Weening, A. J. Verhoeven, and D. Roos. 1989. A phosphoprotein of $M_{\mathrm{r}} 47,000$, defective in autosomal chronic granulomatous disease, copurifies with one of two soluble components required for NADPH: $\mathrm{O}_{2}$ oxidoreductase activity in human neutrophils. J. Clin. Invest. 83:757763.

18. Clark, R. A., H. L. Malech, J. I. Gallin, H. Nunoi, B. D. Volpp, D. Pearson, W. M. Nauseef, and J. T. Curnutte. 1989. Genetic variants of chronic granulomatous disease: prevalence of deficiencies of two cytosolic components of the NADPH oxidase system. N. Engl. J. Med. 321:647-652.

19. Parkos, C. A., M. C. Dinauer, A. J. Jesaitis, S. H. Orkin, and J. T. Curnutte. 1989. Absence of both the $91 \mathrm{kD}$ and $22 \mathrm{kD}$ subunits of human neutrophil cytochrome b in two genetic forms of chronic granulomatous disease. Blood. 73:1416-1420.

20. Bonthron, D. T., C. C. Morton, S. H. Orkin, and T. Collins. 1988. Platelet-derived growth factor A chain: gene structure, chromosomal location, and basis for alternative mRNA splicing. Proc. Natl. Acad. Sci. USA. 85:1492-1496.

21. Maniatis, T., E. Fritsch, and J. Sambrook. Molecular Cloning: a Laboratory Manual. 1982. Cold Spring Harbor Laboratory. Cold Spring Harbor, NY.

22. Feinberg, A. P., and B. Vogelstein. 1983. Anal. Biochem. 132:6-13.

23. Bell, G., J. H. Karam, and W. J. Rutter. 1981. Polymorphic DNA region adjacent to 5 ' end of human insulin gene. Proc. Natl. Acad. Sci. USA. 78:5759-5763.

24. Dinauer, M. C., J. T. Curnutte, H. Rosen, and S. H. Orkin. 1989. A missense mutation in the neutrophil cytochrome $b$ heavy chain in cytochrome-positive $\mathrm{X}$-linked chronic granulomatous disease. J. Clin. Invest. 84:2012-2016.

25. Bruns, G. A. P., B. J. Mintz, A. C. Leary, V. M. Regina, and P. S. Gerald. 1979. Human lysosomal genes: arylsulfatase A and betagalactosidase. Biochem. Genet. 17:1031-1059.

26. Bruns, G. A. P., H. Stroh, G. M. Veldman, S. A. Latt, and J. Floros. 1987. The $35 \mathrm{kD}$ pulmonary surfactant-associated protein is encoded on chromosome 10. Hum. Genet. 76:58-62.

27. Ginsburg, D., R. I. Handin, D. T. Bonthron, T. Donlon, G. A. P. Bruns, S. A. Latt, and S. H. Orkin. 1985. Human von Willebrand Factor (VWF): isolation of complementary DNA (cDNA) clones and chromosomal localization. Science (Wash. DC). 228:1401-1406.

28. McConlogue, L., M. A. D. Brow, and M. A. Innis. 1988. Structure-independent DNA amplification by PCR using 7-deaza-2'-deoxyguanosine. Nucleic Acids Res. 16:9869.

29. Breathnach, R., and P. Chambon. 1981. Organization and expression of eucaryotic split genes coding for proteins. Annu. Rev. Biochem. 58:349-383. 
30. Baehner, R. L., and D. G. Nathan. 1968. Quantitative nitroblue tetrazolium test in chronic granulomatous disease. $N$. Engl. J. Med. 278:971-976.

31. Curnutte, J. T. 1987. Activation of neutrophil NADPH oxidase in a cell-free system. Partial purification of components and characterization of the activation process. J. Biol. Chem. 262:5563-5569.

32. Okamura, N., S. E. Malawista, R. L. Roberts, H. Rosen, H. D. Ochs, B. M. Babior, and J. T. Curnutte. 1988. Phosphorylation of the oxidase-related $48 \mathrm{~K}$ phosphoprotein family in the unusual autosomal cytochrome-negative and $\mathrm{X}$-linked cytochrome-positive types of chronic granulomatous disease. Blood. 72:811-816.

33. Quie, P. G., E. L. Kaplan, A. Page, F. Gruskay, and S. E. Malawista. 1968. Defective polymorphonuclear leukocyte function and chronic granulomatous disease in two female children. $N$. Engl. J. Med. 278:976-980.

34. Reeders, S. T., and C. E. Hildebrand. 1989. Report of the committee on the genetic constitution of chromosome 16. Cytogenet. Cell Genet. 51:299-318.

35. Darras, B. T., M. Zeviani, E. A. Schon, and U. Francke. 1987. Sequences homologous to cytochrome c oxidase subunit IV are located on human chromosomes 14q21-qter and 16q22-q24. Cytogenet. Cell Genet. 46:603.
36. Zeviani, M., M. Nakagawa, J. Herbert, M. I. Lomax, L. I. Grossman, A. A. Sherbany, A. F. Miranda, S. DiMauro, and E. A. Schon. 1987. Isolation of a cDNA clone encoding subunit IV of human cytochrome c oxidase. Gene (Amst.). 55:205-217.

37. Nugent, J. H., W. Gratzer, and A. W. Segal. 1989. Identification of the haem-binding subunit of cytochrome b-245. Biochem. J. 264:921-924.

38. Yamaguchi, T., T. Hayakawa, M. Kaneda, K. Kakinuma, and A. Yoshikawa. 1989. Purification and some properties of the small subunit of cytochrome b558 from human neutrophils. J. Biol. Chem. 264:112-118.

39. Merlie, J. P. 1984. Biogenesis of the acetylcholine receptor, a multisubunit integral membrane protein. Cell. 36:573-575.

40. Kishimoto, T. K., N. Hollander, T. M. Roberts, D. C. Anderson, and T. A. Springer. 1987. Heterogeneous mutations in the B subunit common to the LFA-1, Mac-2 and p150,95 glycoproteins cause leukocyte adhesion deficiency. Cell. 50:193-202.

41. Minami, Y., A. M. Weissman, L. E. Samuelson, and R. D. Klausner. 1987. Building a multichain receptor: synthesis, degradation, and assembly of the T-Cell antigen receptor. Proc. Natl. Acad. Sci. USA. 84:2689-2692. 